\title{
Interactive comment on "Development of the drop Freezing Ice Nuclei Counter (FINC), intercomparison of droplet freezing techniques, and use of soluble lignin as an atmospheric ice nucleation standard" by Anna J. Miller et al.
}

\section{Mingjin Tang (Editor) \\ mingjintang@gig.ac.cn \\ Received and published: 17 October 2020}

The corresponding author (Dr. Nadine Borduas-Dedekind) would like to withdraw this preprint (amt-2020-361) due to co-authorship issues. As a result, the discussion will be closed soon so that the preprint can be withdrawn.

Mingjin Tang AMT associate editor 